\title{
HIV-Associated Nephropathy in an HIV-2-Infected Patient
}

\section{Francisco Martins Do Vale ${ }^{1 *}$, Catarina Abrantes², Maria Lima1, Maria Isabel Casella1, Telma Azevedo ${ }^{1}$, Vítor Laerte Pinto Junior ${ }^{1}$, José Poças ${ }^{1}$}

\author{
${ }^{1}$ Infectious Diseases Department, Hospital de São Bernardo, Centro Hospitalar de Setúbal, Setúbal, Portugal \\ ${ }^{2}$ Nephrology Department, Hospital de São Bernardo, Centro Hospitalar de Setúbal, Setúbal, Portugal \\ Email: *francisco.vale@chs.min-saude.pt
}

How to cite this paper: Vale, F.M.D., Abrantes, C., Lima, M., Casella, M.I., Azevedo, T., Junior, V.L.P. and Poças, J. (2020) HIV-Associated Nephropathy in an HIV-2Infected Patient. World Journal of AIDS, 10, 15-22.

https://doi.org/10.4236/wja.2020.101002

Received: February 7, 2020

Accepted: March 14, 2020

Published: March 17, 2020

Copyright $\odot 2020$ by author(s) and Scientific Research Publishing Inc. This work is licensed under the Creative Commons Attribution International License (CC BY 4.0).

http://creativecommons.org/licenses/by/4.0/

\begin{abstract}
Background: Human immunodeficiency virus (HIV) type 2 infection is predominantly found in West African nations, and approximately $1-2$ million people are thought to be infected. HIV-associated nephropathy (HIVAN) occurs in about $7 \%$ of patients with HIV-1 infection and is one of the most important causes of end-stage renal disease in this population. The only reported case of HIVAN related to HIV-2 infection was described by Izzedine et al. (2006). Aim: The aim of this paper is to report a case of HIVAN in an HIV-2-infected patient, a rarely described condition. Case presentation: We describe a case of a 40-year-old HIV-2-infected female from Angola hospitalized following a six-month history of fever, fatigue, anorexia and weight loss. Laboratory data revealed anaemia, leukopenia and renal dysfunction with nephrotic range proteinuria. Renal biopsy was performed, revealing findings consistent with HIVAN. Also, a presumed diagnosis of ganglionic tuberculosis was established. Conclusion: The slow progression of HIV-2 disease could explain the low frequency of this condition, however, more studies should be carried out for a better understanding of HIV-2 pathophysiology and its associated complications.
\end{abstract}

\section{Keywords}

Acquired Immunodeficiency Syndrome, HIV-Associated Nephropathy, HIVAN, HIV-2

\section{Introduction}

World Health Organisation estimates that 37.9 million people are currently living with human immunodeficiency virus (HIV) [1], of which approximately 1 - 
2 million are thought to be infected with HIV-2 [2]. HIV-2 was first isolated in 1986 from patients with acquired immunodeficiency syndrome (AIDS) originating from Cape Verde islands and Guinea-Bissau [3] and is predominantly found in West African nations, such as Cape Verde, Côte d'Ivoire, Guinea-Bissau, Mali, Nigeria, Senegal, Sierra Leone, and The Gambia. It has also been reported in countries with historical and socio-economic relations to West Africa, like Portugal and its former colonies, such as Angola, Mozambique, Brazil and some parts of India [4]. In 2018, Portugal reported a total amount of 1989 HIV-2 cases, corresponding to $3.3 \%$ of all HIV-infected patients in the country. That year, 29 new diagnoses of HIV-2 infection were reported [5].

The natural history of HIV-2 infection is less well known compared to HIV-1 infection, but HIV-2 seems to cause a more sustained depletion of CD4 T lymphocytes [6] [7] [8]. The transmission rate and plasma viral load are also lower than in HIV-1. This is a possible explanation for the lengthy asymptomatic phase and slower progression to AIDS. The occurrence of severe immunosuppression and its manifestations are similar between the two infections, albeit at a slower rate for HIV-2 [9] [10].

Although a decrease in the incidence of HIV-associated nephropathy (HIVAN) has been observed since the introduction of highly active antiretroviral therapy, HIVAN still represents one of the major causes of end-stage renal disease (ESRD), and is estimated to affect 7\% of HIV-1-infected patients [11]. The occurrence of HIVAN in HIV-2-infected patients is extremely rare and, to the best of our knowledge, only one case has been reported worldwide [12]. In this article, we report a case of HIVAN diagnosis in a patient with long-term HIV-2 infection, presenting to a Portuguese hospital with a febrile and consumptive syndrome.

\section{Case Report}

A 40-year-old HIV-infected Angolan female patient was hospitalized with a six-month history of fever, fatigue, anorexia, and weight loss (14\%). She had been diagnosed with HIV infection 12 years prior, and was under antiretroviral therapy with lamivudine $150 \mathrm{mg}$ QD, zidovudine $300 \mathrm{mg}$ QD, and nevirapine $200 \mathrm{mg}$ BID, initiated four years before, at her home country. Even though she had an undetectable HIV-1 viral load, her CD4 T cell count was 134 cells/mL (13\%). HIV differentiation assay demonstrated the presence of HIV-2 infection. An HIV-2 viral load was performed, which was below the detection level (less than 40 copies $/ \mathrm{mL}$ ).

On admission, she was febrile (tympanic temperature of $38.3^{\circ} \mathrm{C}$ ), and physical examination revealed cachexia (body mass index of $16.53 \mathrm{~kg} / \mathrm{m}^{2}$ ) and microadenopathies on cervical and axillary regions. No other abnormalities, including peripheral oedema or other signs of fluid overload, were found. Moreover, there were no signs of hemodynamic instability (blood pressure 110/70 $\mathrm{mmHg}$ and heart rate 90 beats per minute). 
Blood tests evidenced normocytic and normochromic anaemia $\mathrm{Hb} 8.3 \mathrm{~g} / \mathrm{dL}$ (reference range $11.5-15 \mathrm{~g} / \mathrm{dL}$ ), leukopenia $2.200 / \mu \mathrm{L}(4.500-11.500 / \mu \mathrm{L})$, elevated erythrocyte sedimentation rate $120 \mathrm{~mm} / \mathrm{h}(1-12 \mathrm{~mm} / \mathrm{hh})$ and $\beta 2$-microglobulin $16.69 \mathrm{mg} / \mathrm{L}(0.97-2.64 \mathrm{mg} / \mathrm{dL})$. In addition, lab results showed renal dysfunction with serum urea level $50 \mathrm{mg} / \mathrm{dL}(15-40 \mathrm{mg} / \mathrm{dL})$, a serum creatinine level $2.56 \mathrm{mg} / \mathrm{dL}(0.6-1.1 \mathrm{mg} / \mathrm{dl})$, with an estimated glomerular filtration rate of $26.2 \mathrm{~mL} / \mathrm{min} / 1.73 \mathrm{~m}^{2}$ and a $24 \mathrm{~h}$-urine collection with heavy proteinuria $(5.789 \mathrm{~g})$ without microscopic haematuria. Autoimmunity markers revealed an elevated antinuclear antibody (ANA) level (1:640, homogeneous pattern), a negative anti-double-stranded DNA and anti-extractable nuclear antigens as well as a normal serum complement components (C3 and C4). Serial blood cultures, serology for hepatitis B and C virus infections, and thin blood smear for malaria were all negative.

Full body computed tomography scan revealed in the thoracic window a nodular area of ground-glass opacity at the upper lobe of the right lung, absence of adenopathies, and small bilateral pleural effusion. Transthoracic echocardiography documented a slight circumferential pericardial effusion, and renal ultrasound showed reduced size of both kidneys, and a marked reduction of parenchymal sinus differentiation and diffuse parenchymal hyperechogenicity.

For the etiological diagnosis of renal dysfunction, a renal biopsy was performed, and the results showed chronic tubulointerstitial inflammation in association with areas of microcystic tubular dilatation (Figure 1(a)), features commonly seen in HIVAN. Other biopsy findings were present, such as interstitial fibrosis (Figure 1(b)), involving $70 \%$ of the cortical area, and tubular atrophy. No particular findings were noted in the glomeruli besides total sclerosis in three and two that were hypertrophied. Immunofluorescence was negative for the deposition of immune complexes, supporting the diagnosis of HIVAN.

Despite the presence of serositis, renal dysfunction, leukopenia, and a positive ANA, she had no other clinical criteria for systemic lupus erythematosus (SLE)

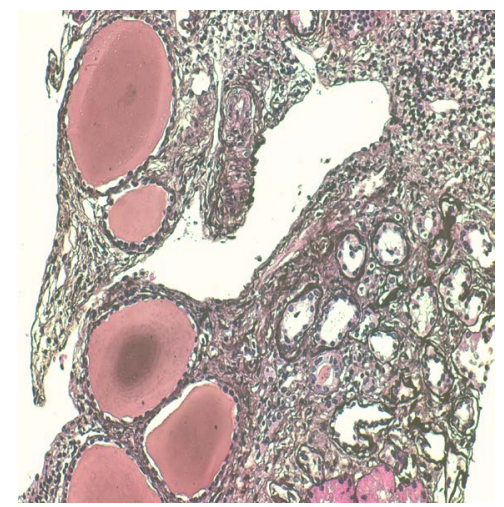

(a)

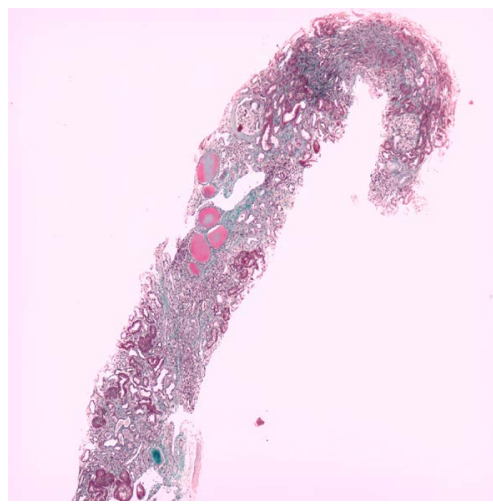

(b)

Figure 1. Kidney biopsy findings. (a) High-power view of tubular cysts (Jones methenamine silver stain, $\times 200$ ); (b) Moderate mononuclear infiltrate associated with interstitial fibrosis, tubular atrophy and focal cystic tubular dilatation (Masson's trichrome stain, $\times 40)$. 
according to the Systemic Lupus International Collaborating Clinics classification criteria [13]. She was however referred to a Rheumatology consultation for further study.

Due to the history of fever, weight loss, anorexia and multiple lymphadenopathies in a patient coming from a country with a high burden of tuberculosis, and despite the lack of positive cultural exams for Mycobacterium tuberculosis or other mycobacteria-including the absence of granulomas in the lymph node excisional biopsy of an axillary node-empirical antibacillary therapy was initiated. After treatment initiation, the patient showed major clinical improvement, sustained apyrexia, showing an increase in appetite, as well as a decrease in lymph node size. After the good results of the therapeutic trial, the presumptive diagnosis of ganglionic tuberculosis was established.

The patient was started on antiretroviral therapy with a regimen containing abacavir, lamivudine, and dolutegravir was adjusted to renal function. She was discharge on day 45 of inpatient treatment, with clinical improvement, normalized inflammatory markers and stabilized renal function. Follow-up on the Infectious Diseases Department and Nephrology Department were scheduled.

At the moment, with six months of follow-up, the patient remains asymptomatic, a weight gain of $20 \mathrm{~kg}$ was observed (current body mass index of 23.88 $\mathrm{kg} / \mathrm{m}^{2}$ ) and no clinical complications were reported. She reports $100 \%$ compliancy to the antiretroviral regimen initiated and viral load remains undetectable with a progressive increase of $\mathrm{CD} 4 \mathrm{~T}$ cell count. The last available value of CD4 T lymphocytes count was 458 cells $/ \mathrm{mL}$ ( $\Delta 324$ cell $/ \mathrm{mL}$ ), with $22 \%(\Delta 9 \%)$. She continues under antibacillary therapy for ganglionic tuberculosis, currently with a two-drug regimen, and will complete year of treatment. The renal function stabilized, with a current estimated glomerular filtration rate of 24.9 $\mathrm{mL} / \mathrm{min} / 1.73 \mathrm{~m}^{2}$ and urinary protein excretion of $3.900 \mathrm{~g}$.

Rheumatology medical doctors ruled out the diagnosis of SLE, and she was discharged from this consult.

\section{Discussion}

HIVAN was first described in 1984 as a complication of AIDS [14] [15], although HIVAN may also occur in patients with less advanced HIV infection or following acute seroconversion [16] [17]. HIVAN is considered to be a subtype of focal and segmental glomerulosclerosis, found in about $7 \%$ of HIV-1-infected patients [11] and is one of the most important causes of ESRD in this population [18] [19]. Some risk factors have been associated with the development of HIVAN and its progression to ESRD such as African American ancestry, APOL1 polymorphisms, comorbidities, high viral load, low CD4 T cell count, advanced kidney disease and nephrotic range proteinuria [19]. Currently, risk factors for HIVAN in HIV-2-infected patients are unknown, but it is believed that it could be similar. Our patient had several of the previously stated factors, namely, African ancestry, low CD4 $\mathrm{T}$ cell count, advanced kidney disease and nephrotic range proteinuria at presentation. 
Clinically, HIVAN usually presents with nephrotic range proteinuria and acute renal failure [20]. A broad spectrum of renal disorders can be seen in association with HIV infection. Indeed, during initial diagnostic workup, we believed that renal impairment was caused by SLE. Other glomerular disorders may have a clinical presentation comparable with HIVAN and must be part of differential diagnosis. These conditions are amyloidosis, post-infectious glomerulonephritis, thrombotic microangiopathy, diabetic nephropathy, classic focal segmental glomerulosclerosis, minimal change disease, and immune complex-mediated glomerulonephritis such as IgA nephropathy, membranous nephropathy, membranoproliferative glomerulonephritis associated with concurrent hepatitis $\mathrm{C}$ infection, and lupus-like proliferative glomerulonephritis [19] [21].

Kidney biopsy is crucial to establish a correct diagnosis, for therapeutic guidance and to foresee the subsequent outcome of the renal function. The histopathological alterations include signs of tubulointerstitial disease and microcystic tubular dilatation, but typical collapsing glomerulopathy may also be present [22]. Based on these findings, a diagnosis of HIVAN can be established.

Only one other case of HIVAN related to HIV-2 infection has been described in the scientific literature [12]. In both cases, the patients were of African ancestry (although the other study does not specify the country), had a similar clinical presentation, and both presented with heavy proteinuria of about $5.000 \mathrm{~g}$. However, our patient also presented persistent fever. We started empirical treatment for ganglionic tuberculosis since all other investigations were inconclusive. Another difference identified was the probably longer course of the disease that may justify the higher serum creatinine level on our patient.

A study conducted by Ferreira et al. (2011) that characterized the type of renal disease in Portuguese HIV-infected patients identified three HIV-2-infected patients, but all had other causes for the kidney injury not related to the HIV infection [23].

Most of the treatment options for HIVAN in HIV-1-infected patients are based on retrospective studies and small non-randomized trials. They include combined antiretroviral therapy, which, by itself, reduces by $60 \%$ the risk to develop HIVAN [24], renin-angiotensin-aldosterone system inhibitors, corticosteroids and, eventually, renal replacement therapy and kidney transplantation [19] [21]. We started losartan $12.5 \mathrm{mg}$ QD, along with antiretroviral therapy.

HIV-2 is intrinsically resistant to first-generation nonnucleoside reverse transcriptase inhibitors [25] and the fusion inhibitor enfuvirtide [26], so these agents should not be used. Our patient was initially medicated with nevirapine, probably because of a lack of differentiation methods to diagnose HIV-2 infection in Angola, which would explain the low levels of CD4 T cell count at presentation. Possibly, the delay in starting an effective antiretroviral therapy may have been decisive in the evolution to HIVAN. Since the patient planned to travel back to her home country her antiretroviral medication was switched to tenofovir alafenamide $10 \mathrm{mg}$ QD, emtricitabine $200 \mathrm{mg}$ QD and lopinavir $400 \mathrm{mg}$ plus ritonavir $100 \mathrm{mg}$ BID. When empirical treatment for tuberculosis was initiated, and 
considering drug-to-drug interactions, the medication was switched to abacavir, lamivudine and dolutegravir (the latter being administered twice a day). Later on, antiretroviral therapy was simplified since she decided to take residency in Portugal considering the need for continuous health care, and better drug options.

\section{Conclusion}

In this article, we reported a case of HIVAN in the context of HIV-2 infection. As far as we know, only one case was reported worldwide, demonstrating the rarity of this entity or most probably the lack of knowledge in this area. Moreover, there are several issues regarding the diagnosis and management of HIV-2-infected patients that are not well known. More studies should be carried out, and case reports like this one, for a better understanding of HIV-2 pathophysiology and its associated complications. Another important highlight of this article is the importance of the correct identification of HIV-2 infection, which allows for the right choice of antiretroviral therapy and therefore the correct treatment of patients and prevention of long-term complications.

\section{Acknowledgements}

The authors would like to thank Dr. Helena Sousa and Dr. Mário Góis from the Adolfo Coelho Renal Morphology Laboratory, Hospital Curry Cabral in Lisbon, Portugal, for kindly providing the images of renal histopathology.

\section{Consent for Publication}

A signed consent form was obtained from this patient for the publication of this case report.

\section{Conflicts of Interest}

The authors declare no conflicts of interest regarding the publication of this paper.

\section{References}

[1] World Health Organisation (2019) HIV/AIDS. http://who.int/hiv/en

[2] Gottlieb, G.S., Eholie, S.P., Nkengasong, J.N., Jallow, S., Rowland-Jones, S., Whitlle, H.C., et al. (2008) A Call for Randomized Controlled Trials of Antiretroviral Therapy for HIV-2 Infection in West Africa. AIDS, 22, 2069-2074. https://doi.org/10.1097/QAD.0b013e32830edd44

[3] Clavel, F., Guetard, D., Brun-Vezinet, F., Chamaret, S., Rey, M.A., Santos-Ferreira, et al. (1986) Isolation of a New Human Retrovirus from West African Patients with AIDS. Science, 233, 343-346. https://doi.org/10.1126/science.2425430

[4] de Silva, T.I., Cotten, M. and Rowland-Jones, S.L. (2008) HIV-2: The Forgotten AIDS Virus. Trends in Microbiology, 16, 588-595. https://doi.org/10.1016/j.tim.2008.09.003

[5] Portugal. Ministério da Saúde. Direção-Geral da Saúde/Instituto Nacional de Saúde 
Doutor Ricardo Jorge (2019) Infeção VIH e SIDA em Portugal. DGS/INSA, Lisboa. http://www.insa.min-saude.pt/relatorio-infecao-vih-e-sida-em-portugal-2019

[6] Popper, S.J., Sarr, A.D., Travers, K.U., Guèye-Ndiaye, A., Mboup, S., Essex, M.E., et al. (1999) Lower Human Immunodeficiency Virus (HIV) Type 2 Viral Load Reflects the Difference in Pathogenicity of HIV-1 and HIV-2. The Journal of Infectious Diseases, 180, 1116-1121. https://doi.org/10.1086/315010

[7] MacNeil, A., Sarr, A.D., Sankale, J.L., Meloni, S.T., Mboup, S. and Kanki, P. (2007) Direct Evidence of Lower Viral Replication Rates in Vivo in Human Immunodeficiency Virus Type 2 (HIV-2) Infection than in HIV-1 Infection. Journal of Virology, 81, 5325-5330. https://doi.org/10.1128/JVI.02625-06

[8] Campbell-Yesufu, O.T. and Gandhi, R.T. (2011) Update on Human Immunodeficiency Virus (HIV)-2 Infection. Clinical Infectious Diseases, 52, 780-787. https://doi.org/10.1093/cid/ciq248

[9] Matheron, S., Pueyo, S., Damond, F., Simon, F., Leprêtre, A., Campa, P., et al. (2003) Factors Associated with Clinical Progression in HIV-2 Infected Patients. AIDS, 17, 2593-2601. https://doi.org/10.1097/00002030-200312050-00006

[10] Esbjõrnsson, J., Mansson, F., Kvist, A., da Silva, Z.J., Andersson, S., Fenyö, E.M., et al. (2018) Long-Term Follow-Up of HIV-2-Related AIDS and Mortality in Guinea-Bissau: A Prospective Open Cohort Study. The Lancet HIV. https://doi.org/10.1016/S2352-3018(18)30254-6

[11] Shahinian, V., Rajaraman, S., Borucki, M., Grady, J., Hollander, W.M. and Ahuja, T.S. (2000) Prevalence of HIV-Associated Nephropathy in Autopsies of HIV Infected Patients. American Journal of Kidney Diseases, 35, 884-888. https://doi.org/10.1016/S0272-6386(00)70259-9

[12] Izzedine, H., Damond, F., Brocheriou, I., Ghosn, J., Lassal, H. and Deray, G. (2006) HIV-2 Infection and HIV-Associated Nephropathy. AIDS, 20, 949-950. https://doi.org/10.1097/01.aids.0000218566.05274.2b

[13] Petri, M., Orbai, A.M., Alarcon, G.S., Gordon, C., Merrill, J.T., Fortin, P.R., et al. (2012) Derivation and Validation of the Systemic Lupus International Collaborating Clinics Classification Criteria for Systemic Lupus Erythematosus. Arthritis \& Rheumatology, 64, 2677-2686. https://doi.org/10.1002/art.34473

[14] Pardo, V., Aldana, M., Colton, R.M., Fischl, M.A., Jaffe, D., Moskowitz, L., et al. (1984) Glomerular Lesions in the Acquired Immunodeficiency Syndrome. Annals of Internal Medicine, 101, 429-434. https://doi.org/10.7326/0003-4819-101-4-429

[15] Rao, T.K., Filippone, E.J., Nicastri, A.D., Landesman, S.H., Frank, E., Chen, C.K., et al. (1984) Associated Focal and Segmental Glomerulosclerosis in the Acquired Immunodeficiency Syndrome. The New England Journal of Medicine, 310, 669. https://doi.org/10.1056/NEJM198403153101101

[16] Wiston, J.A., Bruggeman, L.A., Ross, M.D., Jacobson, J., Ross, L., D’Agati, V.D., et al. (2001) Nephropathy and Establishment of a Renal Reservoir of HIV Type 1 during Primary Infection. The New England Journal of Medicine, 344, 1979.

https://doi.org/10.1056/NEJM200106283442604

[17] Levin, M.L., Palella, F., Shah, S., Lerma, E., Butter, J. and Kanwar, Y.S. (2001) HIV-Associated Nephropathy Occurring before HIV Antibody Seroconversion. American Journal of Kidney Diseases, 37, e39. https://doi.org/10.1016/S0272-6386(05)90003-6

[18] Mocroft, A., Reiss, P., Gasiorowski, J., Ledergerber, B., Kowalska, J., Chiesi, A., et al. (2010) Serious Fatal and Nonfatal Non-AIDS-Defining Illnesses in Europe. Journal of Acquired Immune Deficiency Syndromes, 55, 262-270. 
https://doi.org/10.1097/QAI.0b013e3181e9be6b

[19] Waheed, S. and Atta, M.G. (2014) Predictors of HIV-Associated Nephropathy. EXpert Review of Anti-Infective Therapy, 12, 555-563. https://doi.org/10.1586/14787210.2014.901170

[20] Swanepoel, C.R., Atta, M.G., D’Agati, V.D., Estrella, M.M., Fogo, A.B., Naicker, S., et al. (2018) Kidney Disease in the Setting of HIV Infection: Conclusions from a Kidney Disease: Improving Global Outcomes (KDIGO) Controversies Conference. Kidney International, 93, 545-559. https://doi.org/10.1016/j.kint.2017.11.007

[21] Palau, L., Menez, S., Rodriguez-Sanchez, J., Novick, T., Delsante, M., McMahon, B.A., et al. (2018) HIV-Associated Nephropathy: Links, Risks and Management. HIV Aids (Auckl), 10, 73-81. https://doi.org/10.2147/HIV.S141978

[22] Fogo, A.B., Lusco, M.A., Najafian, B. and Alpers, C.E. (2016) AJKD Atlas of Renal Pathology: HIV-Associated Nephropathy (HIVAN). American Journal of Kidney Diseases, 68, e13-e14. https://doi.org/10.1053/j.ajkd.2016.06.002

[23] Ferreira, A.C., Carvalho, D., Carvalho, F., Galvão, M.J. and Nolasco, F. (2011) Renal Pathology in Portuguese HIV-Infected Patients. Portuguese Journal of Nephrology and Hypertension, 25, 275-283.

[24] Lucas, G.M., Eustace, J.A., Sozio, S., Mentari, E.K., Appiah, K.A. and Moore, R.D. (2004) Highly Active Antiretroviral Therapy and the Incidence of HIV-1-Associated Nephropathy. AIDS, 18, 541-546.

https://doi.org/10.1097/00002030-200402200-00022

[25] Ntemgwa, M.L., d'Aquin Toni, T., Brenner, B.G., Camacho, R.J. and Wainberg, M.A. (2009) Antiretroviral Drug Resistance in Human Immunodeficiency Virus Type 2. Antimicrobial Agents and Chemotherapy, 53, 3611-3619. https://doi.org/10.1128/AAC.00154-09

[26] Witvrouw, M., Pannecouque, C., Switzer, W.M., Folks, T.M., De Clercq, E. and Heneine, W. (2004) Susceptibility of HIV-2, SIV and SHIV to Various Anti-HIV-1 Compounds: Implications for Treatment and Postexposure Prophylaxis. Antiviral Therapy, 9, 57-65. 